\title{
Research on the Intelligent Control and Simulation of Automobile Cruise System Based on Fuzzy System
}

\author{
Xue-wen Chen, ${ }^{1}$ Jin-guo Zhang, ${ }^{1}$ and Yan-jun Liu ${ }^{2}$ \\ ${ }^{1}$ College of Automobile and Traffic Engineering, Liaoning University of Technology, Jinzhou 121001, China \\ ${ }^{2}$ College of Science, Liaoning University of Technology, Jinzhou, Liaoning 121001, China \\ Correspondence should be addressed to Xue-wen Chen; xuewen.chen@163.com
}

Received 23 March 2016; Accepted 17 May 2016

Academic Editor: Xinkai Chen

Copyright (c) 2016 Xue-wen Chen et al. This is an open access article distributed under the Creative Commons Attribution License, which permits unrestricted use, distribution, and reproduction in any medium, provided the original work is properly cited.

\begin{abstract}
In order to improve the active safety driving vehicle and alleviate the intension of driving fatigue, an intelligent control strategy of automobile cruise is put forward based on the throttle or braking pedal combined control adopting the fuzzy control theory. A fuzzy logic controller is presented, which consists of the two input variables, the deviation of the theoretical safe distance and relative distance and the relative velocity between the preceding vehicle and the cruise vehicle, and the single output variable, that is, the throttle opening or the braking pedal travel. Taking the test data of $1.6 \mathrm{~L}$ vehicle with auto-transmission as an example, the function on the intelligent cruise control system is simulated adopting MATLAB/Simulink aiming at different working conditions on the city road. The simulation results show that the control strategy possesses integrated capability of automated Stop \& Go control, actively following the preceding vehicle on the conditions of keeping the safety distance and the constant velocity cruise. The research results can offer the theory and technology reference for setting dSPACE type and developing the integrated control product of automobile cruise system.
\end{abstract}

\section{Introduction}

Recently, traffic jam is getting more and more serious and traffic accident rate continues to rise in every major city of the world that townspeople's travel environment and life safety are influenced seriously. As safety assistant driving system, the adaptive cruise control (ACC) and Stop \& Go have been regarded as a hot issue in both academia and automatic industry, especially in vehicle's intelligent safety controlling field. It is generally known that ACC system is mainly used in highway driving condition only at speeds above $40 \mathrm{~km} / \mathrm{h}$ for luxury vehicles, and it is not suitable for city traffic flow with the high density and the slow speed. It is worth mentioning that Stop \& Go systems are applied to deal with the city traffic condition at $40 \mathrm{~km} / \mathrm{h}$ or below. Compared with conventional ACC system, the Stop \& Go system can effectively identify the front vehicle cutting in the cruise lane or changing to the other lane and realize vehicle's stationary control at low speeds to avoid speeding up and down all the time. In addition, the system can release the driver from frequently handling the vehicle, only taking driver's steering control even when it is stuck in traffic due to its automatic Stop \& Go control function. Through above analysis we can see that any system has its own scope of application. Therefore, an intelligent cruise system to achieve the integration of two kinds of control functions for cruise system can greatly improve or perfect the function of a single system control.

In the previous researches, there has been a large collection of papers on ACC systems aimed at highways [1-5], but only a few researches have paid attention to the Stop \& Go system used for the city traffic condition [6-9]. The research on combining the ACC system with the Stop \& Go systems has not been extensively discussed until recently [10]. Fuzzy control theory is considered as one of the powerful tools for achieving the goal because it does not rely on an accurate mathematical model $[9,11-14]$, and it represents the human reasoning methods in a very effective way and it is suitable for dealing with nonlinear and uncertainty control system [15-18]. Naranjo et al. proposed a fuzzy control strategy to implement the two functions of the ACC and Stop \& Go control to an electric van equipped with GPS sensors to measure 


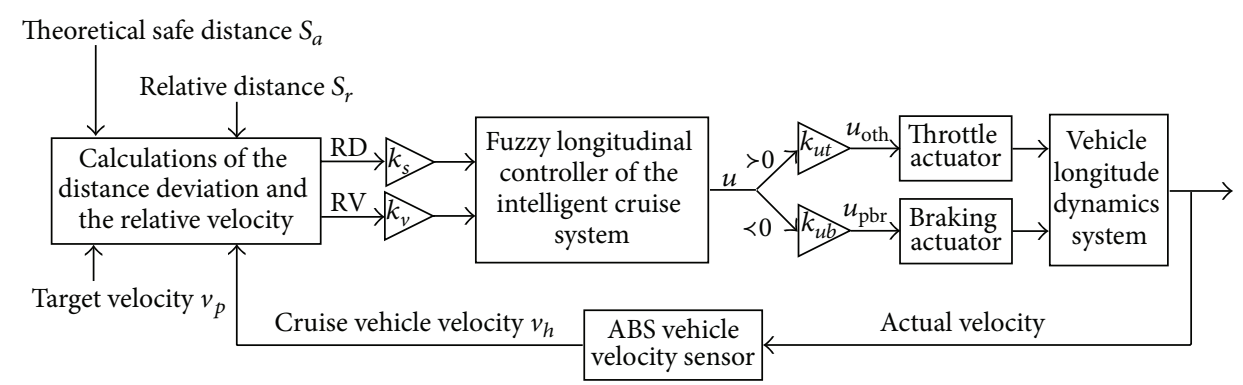

FIGURE 1: Principle diagram of the fuzzy longitudinal control on automobile intelligent cruise system.

the relative speed and distance between the preceding vehicle and cruise vehicle by adopting throttle control only. Then, Naranjo et al. further considered the synthetic control of accelerator and brake using 13 fuzzy rules and a test showed that the unmanned vehicles based on the fuzzy rules like human-driven vehicles adapt to any kind of condition in a great scope of speeds [19]. Zhu has put forward a control strategy on ACC based on the preview acceleration model and verified its control function. Pei et al. has proposed a layered algorithm for adaptive cruise control [20]. In upper layer, a safe headway maintenance algorithm is devised based on driver's vehicle-following characteristics, enabling the smooth switching of control modes according to different working conditions; while in bottom layer, a throttle controller and a brake controller are designed, respectively, with feedforward and feedback control. Tests on the sudden cut-in and emergent deceleration of front vehicle are performed to verify the layered algorithm.

Although ACC system has been researched extensively, in some ways it remains to be strengthened, for example, further study on intelligent cruise control algorithm, especially combining the ACC system with the Stop \& Go systems and the further developing of integrated system product [20-22].

It is our goal to propose an intelligent cruise control strategy based on the throttle or braking pedal combined control adopting the fuzzy control theory. Although the proposed fuzzy control strategy is not new in theory, it has combined the ACC system functions with the Stop \& Go systems functions in a unified control framework in this paper. The fuzzy logic controller consists of the two input variables, that is, the deviation of the theoretical safe distance and the actual relative distance and the relative speed between the preceding target vehicle and the cruise vehicle, and the single output variable, that is, the throttle opening or the braking pedal travel (nonbraking force). It is easily accomplished for the high-speed ACC driving and low-speed Stop \& Go control based on proposed fuzzy logic controller. Taking the test data of $1.6 \mathrm{~L}$ vehicle with auto-transmission as an example, the simulation module on the cruise system is designed adopting MATLAB/Simulink and the varying of the typical traffic running cases is validated. The experimental results show that the proposed control strategy is effective for integrating the highspeed ACC strategy and low-speed Stop \& Go performance.

\section{Intelligent Control on Automobile Cruise System}

2.1. Intelligent Cruise Control Scheme. Figure 1 describes a logical diagram on the intelligent cruise system. In Figure 1 the input variables of the fuzzy controller are the deviation of the theoretical safe distance $S_{a}$ and relative distance $S_{r}$ and the relative velocity between the preceding target vehicle velocity $v_{p}$ and the cruise vehicle velocity $v_{h}$, where the theoretical safety distance $S_{a}$ can be obtained by following expression considering the response time of the drivers $t_{f}$, the response time of brake system $t_{x}$, the braking force increasing time $t_{s}$, the deceleration of the cruise vehicle $a_{h}$ and the stopping distance $d_{0}, S_{a}=v_{h} \cdot\left(t_{f}+t_{s} / 2+t_{x}\right)+v_{h}{ }^{2} / 2 a_{h}+d_{0}$. Here, the theoretical safe distance $S_{a}$ is relatively secure because the preceding vehicle is stationary for assumptions. The relative distance $S_{r}$ can be measured by Lidar. The deviation of the distance $\mathrm{RD}$ is calculated from the difference of the theoretical safety distance and the actual measured distance, that is, $\mathrm{RD}=S_{a}-S_{r}$.

The deviation of the speed, that is, the relative speed RV, is obtained from the speed difference of the preceding target vehicle and the cruise vehicle, that is, $R V=v_{p}-v_{h}$. The output variable of the longitudinal controller is the actual signal $u$; it represents the throttle opening or the braking pedal travel. One important thing to note about range of the value $u$ is the interval value from -100 to 100 . If the value $u$ is greater than zero, then the control signal will be converted to a corresponding PWM command and the throttle actuator will generate an action to accelerate based on the PWM command. On the contrary, if the value $u$ is less than zero, an action to decelerate is actuated by regulating the brake pedal travel based on the braking PWM signal. According to the PWM command, the vehicle longitude dynamics system will produce a pull force to control two actuators to regulate the throttle opening and the brake pedal travel. Therefore, the cruise vehicle will be accelerated or decelerated to obtain eventually the actual speed by ABS vehicle speed sensor, which is used to calculate the relative velocity.

Figure 2 shows the control procedure of the intelligent cruise system. Note that the proposed fuzzy controller will be motivated from 0 to $120 \mathrm{~km} / \mathrm{h}$. The relative distance $S_{r}$ can be measured by Lidar when a target vehicle appears in 


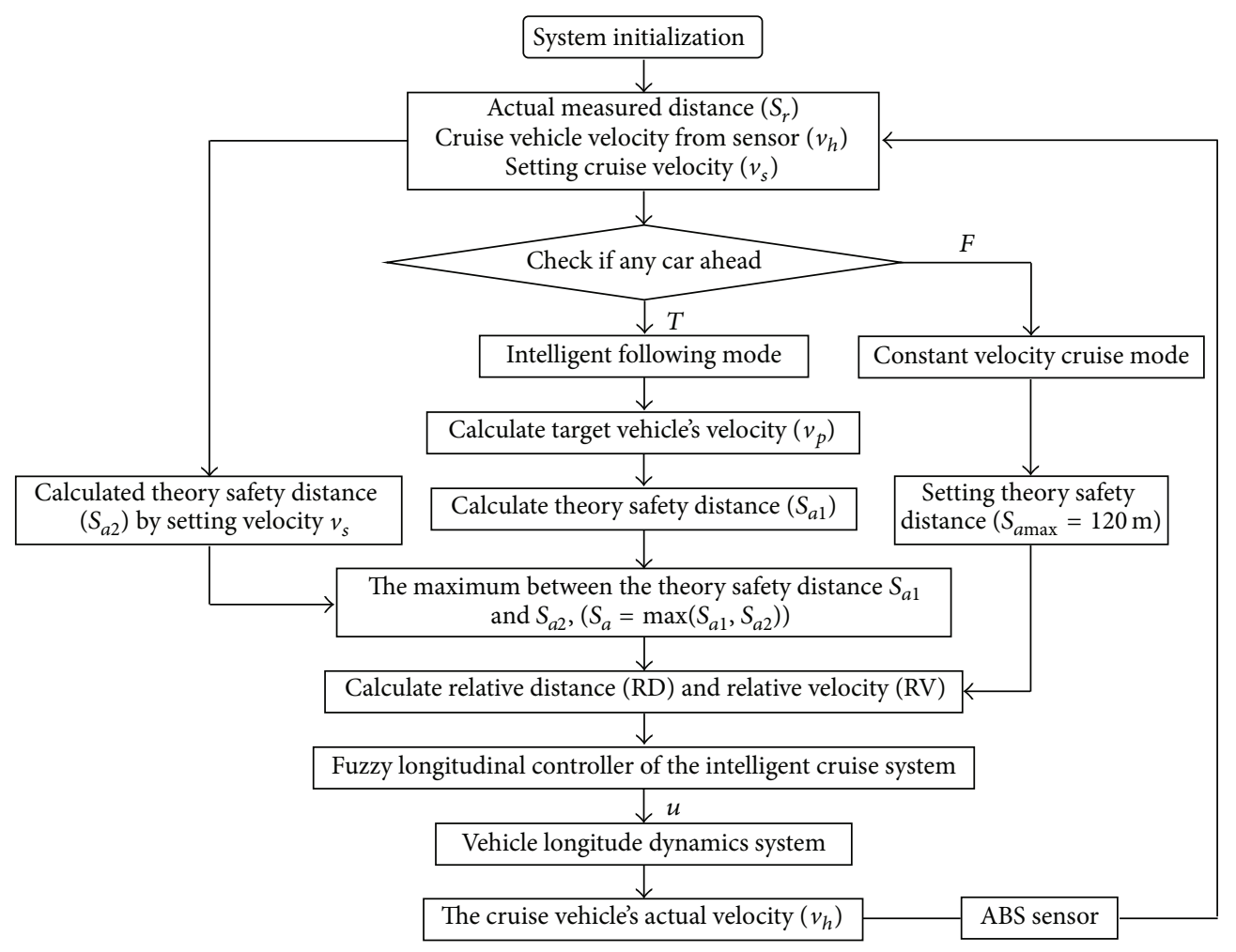

FIGURE 2: Sketch map of the control procedure on the intelligent cruise control.

front of the cruise vehicle. The velocity information from the cruise vehicle $v_{h}$ is provided by its ABS vehicle speed sensor. According to the actual measured distance $S_{r}$ and the velocity from the cruise vehicle $v_{h}$, the velocity of the preceding target vehicle $v_{p}$ can be obtained. On the basis of the above collected information, the distance deviation and the relative velocity between two vehicles are calculated. In Figure 2, there are two patterns to calculate the distance deviation, RD. For the first pattern, namely, the CCS mode, the relative distance $S_{r}$ is supposed to be 120 meters if there was no target vehicle in front of the cruise vehicle. For the second pattern, namely, the intelligent following mode, the theoretical safe distance $S_{r}$ is regarded as the maximum derived from the product of the total time which was mentioned previously and the velocity $v_{p}$ from the preceding target vehicles or the desired cruise speed $v_{h}$ was set beforehand by the driver.

\subsection{Fuzzy Controller Design}

2.2.1. Fuzzification of Input and Output Variable. Fuzzification translates each numerical input into a set of fuzzy classes. There are two inputs variables $\mathrm{RD}$ and $\mathrm{RV}$ into the fuzzy longitudinal controller. The output variable $u$ of the longitudinal controller is the throttle opening or the braking pedal travel. The two inputs and the output of the longitudinal controller are transferred into five fuzzy language variables, including NB (Negative Big), NM (Negative Middle), ZO (Zero), PM (Positive Middle), and PB (Positive Big). The alterable domain range for the $\mathrm{RD}, \mathrm{RV}$, and $u$ is, respectively, the interval value from -35 to $35,-13$ to 13 , and -100 to 100 . Of

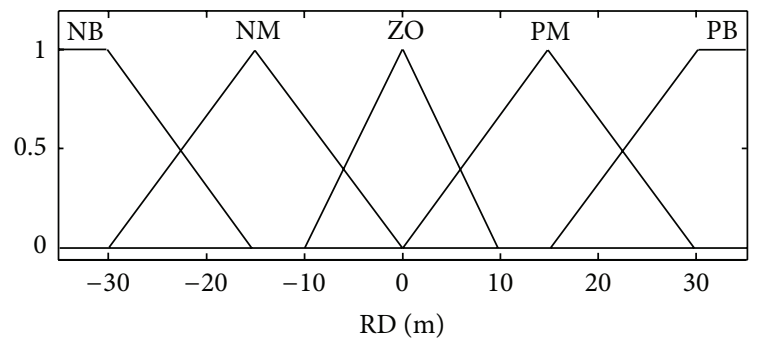

FIgURE 3: Membership function of the relative distance RD (or RV).

course, the alterable domain range is adjustable according to the actual condition. For some of these input and output variables of the longitudinal controller, the value range, the distribution, and shape of these membership functions are shown in Figures 3 and 4.

2.2.2. Construct Rule Base. The fuzzy rule base accumulates a great amount of special knowledge and experience, thereby including 25 simple control rules. Fuzzy control rules are characterized by if-then statements involving fuzzy linguistic variables. For example, the generic form of the fuzzy rules in the case of MISO is

$$
\begin{aligned}
& \text { If } x \text { is } A_{i}, \ldots \text {, and } y \text { is } B_{i} \text {, Then } z \text { is } C_{i} \text {, } \\
& \qquad i=1,2, \ldots, n .
\end{aligned}
$$

For Table 1, if the deviation of the distance RD is NB and the relative speed $\mathrm{RV}$ is $\mathrm{NB}$, then the control $u$ is $\mathrm{ZO}$. This rule 
TABLE 1: Fuzzy control rule.

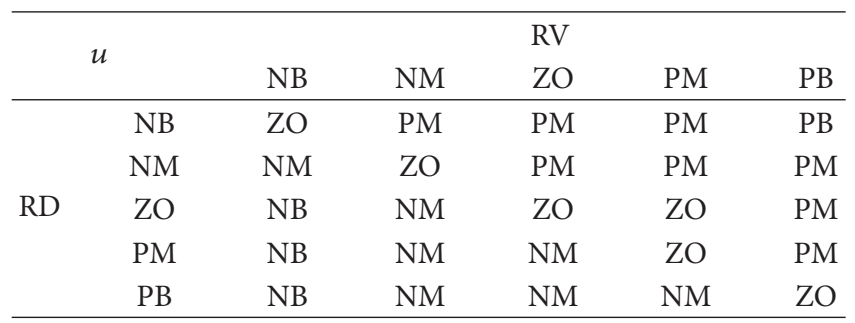

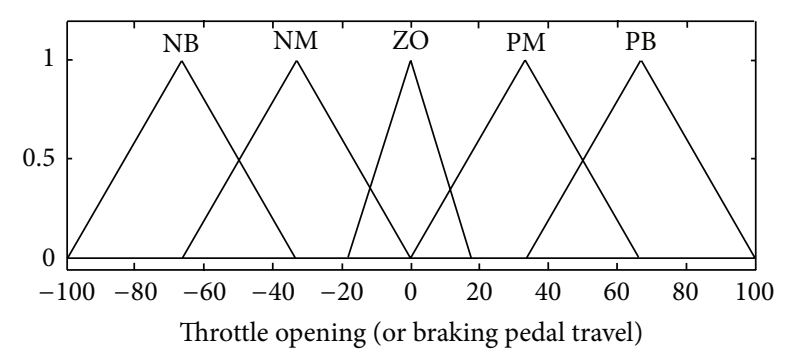

FigUre 4: Membership function of output variable $u$.

denotes that the cruise vehicle is fast approaching the target vehicle but the actual distance between two vehicles is very far; then the throttle opening will remain the same. At this point, the relative distance between the cruise vehicle and the target vehicle is shortened gradually. Also, if the deviation of the distance $\mathrm{RD}$ is $\mathrm{PB}$ and the relative speed $\mathrm{RV}$ is $\mathrm{NB}$, then the output $u$ is NB. This rule denotes that the cruise vehicle is rapidly approaching the target vehicle ahead and the actual distance between two vehicles is quite close, then the braking system actuator will regulate quickly and actively the brake pedal travel to significantly reduce the cruise vehicle's velocity in order to avoid rear-end collision. Similarly, other fuzzy control rules are easily comprehended as well.

2.2.3. Defuzzification. The defuzzifier is utilized to yield a nonfuzzy decision or control action from an inferred fuzzy control action by the fuzzy reasoner [23-25]. The method on the center of gravity is used to calculate the defuzzified output as follows:

$$
U=\frac{\sum_{i=1}^{N} \omega_{i} u_{i}}{\sum_{i=1}^{N} \omega_{i}},
$$

where $N$ is the number of fuzzy rules, $u_{i}$ is the output of fuzzy rule base, and $\omega_{i}$ is the weight of $u_{i}$.

\subsection{Intelligent Cruise System Dynamics Modeling. In order to} verify the function on the intelligent cruise control system adopting Simulink, it is necessary to establish the vehicle dynamics modeling of the intelligent cruise system. As can be seen from Figure 5, the model mainly includes five parts that are electronic controlled engine module, hydraulic torque converter module, automatic mechanical transmission module, vehicle running system module, and vehicle braking system module. Each module or subsystem is connected by the relations between the torque and speed. From the whole module of vehicle longitude dynamics system the actual velocity of the cruise vehicle is derived. The actual speed is fed back to the deviation calculation of the fuzzy controller presented above by ABS vehicle velocity sensor.

Equation (3) describes the mechanical characteristics of the cruise system dynamics supposing the cruise vehicle drives on smooth surfaces and not taking into account wheel slip action to the vehicle body as follows:

$$
\begin{aligned}
\left(m+\frac{I_{f}+I_{r}}{r^{2}}\right) \dot{v}_{h}= & \frac{T_{s}}{r}-\frac{T_{b f}+T_{b r}}{r}-m g f \\
& -\frac{1}{2} \rho C_{d} A\left(v+v_{w}\right)^{2},
\end{aligned}
$$

where $r$ is the wheel rolling radius, $I_{f}$ represents the summation of the front wheel's moment of inertia, and $I_{r}$ is the summation of the rear wheel's moment of inertia, $T_{b f}$ and $T_{b r}$ represent the brake torque of the front and rear wheel, $C_{d}$ is a drag coefficient and $A$ is vehicle's windward area, $v_{w}$ is the wind velocity, $m$ is the cruise vehicle's total mass, $g$ is the gravitational acceleration, and $f$ is the rolling resistance coefficient.

The driving wheels torque $T_{s}$ is generated through the engineer and whole transmission systems and it is expressed as

$$
T_{s}=\eta_{t} T_{0} i_{0}=\eta_{t} T_{t} i_{g} i_{0}
$$

$T_{0}$ and $T_{t}$ denote the value of the gearbox output shaft and the turbine torque, respectively, $i_{g}$ represents the gear ratio, $i_{0}$ is the final driver ratio, and $\eta_{t}$ is the transmission system transfer coefficient.

Supposing the components between the impeller and turbine are rigid without the plastic deformation, then the turbine torque $T_{t}$ is derived as follows:

$$
\frac{T_{t}}{T_{p}}=\tau\left(\frac{n_{t}}{n_{p}}\right)
$$

where $n_{t}$ and $n_{p}$ represent the rotation speed of the turbine and impeller in rpm, respectively, $\tau$ is the torque coefficient, and $T_{p}$ denotes the value of the impeller torque and has been deduced by the following formula:

$$
\frac{T_{p}}{n_{p}^{2}}=K_{\mathrm{tc}}\left(\frac{n_{t}}{n_{p}}\right)
$$

where $K_{\mathrm{tc}}$ denotes the torque coefficient; the relation between the impeller torque and the engine torque can be calculated as follows:

$$
I_{e} \dot{\omega}_{e}=T_{\text {ed }}-T_{p},
$$

where $T_{\text {ed }}$ represents the engine torque, which can be measured based on engineer dynamometer. The value relies on two parameters as the engine revolution $n_{e}$ and the throttle opening $u$ in 0-1 range. The relationship among engine torque, engine revolution, and throttle opening is normally expressed as engine torque characteristic map like 


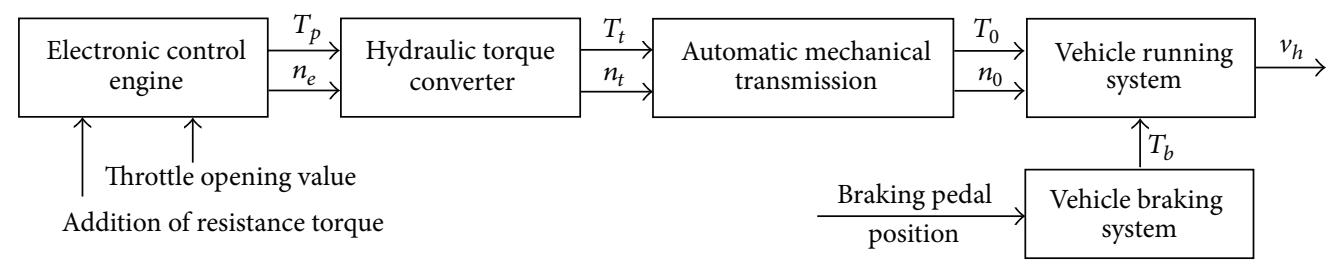

FIGURE 5: A module of vehicle longitude dynamics system.

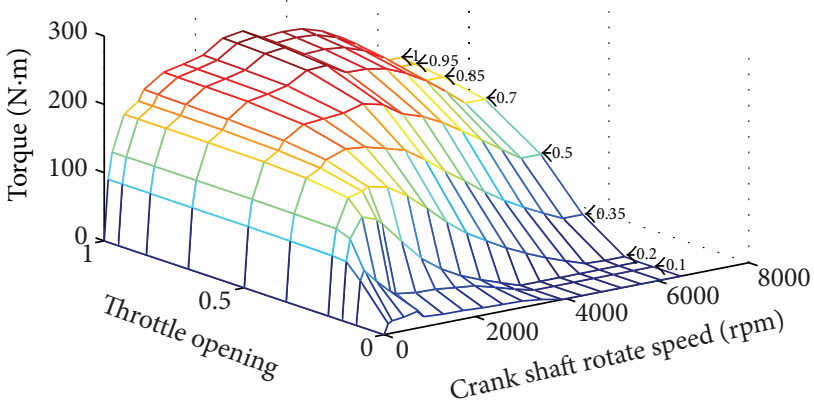

(a) Engine torque characteristic

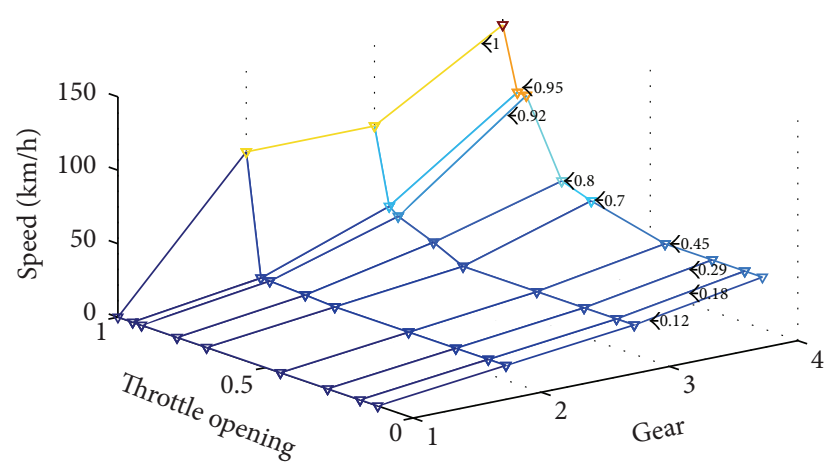

(b) Downshift switchover process

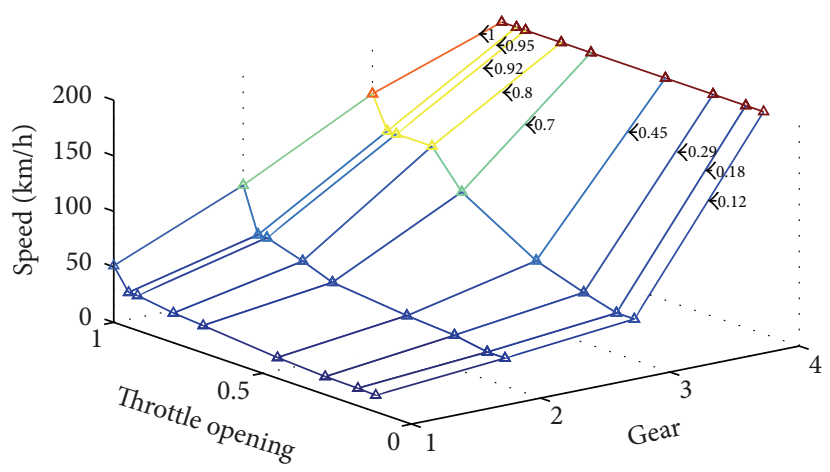

(c) Upshift switchover process

FIGURE 6: Engine torque characteristic and gear switch logic of automatic transmission.

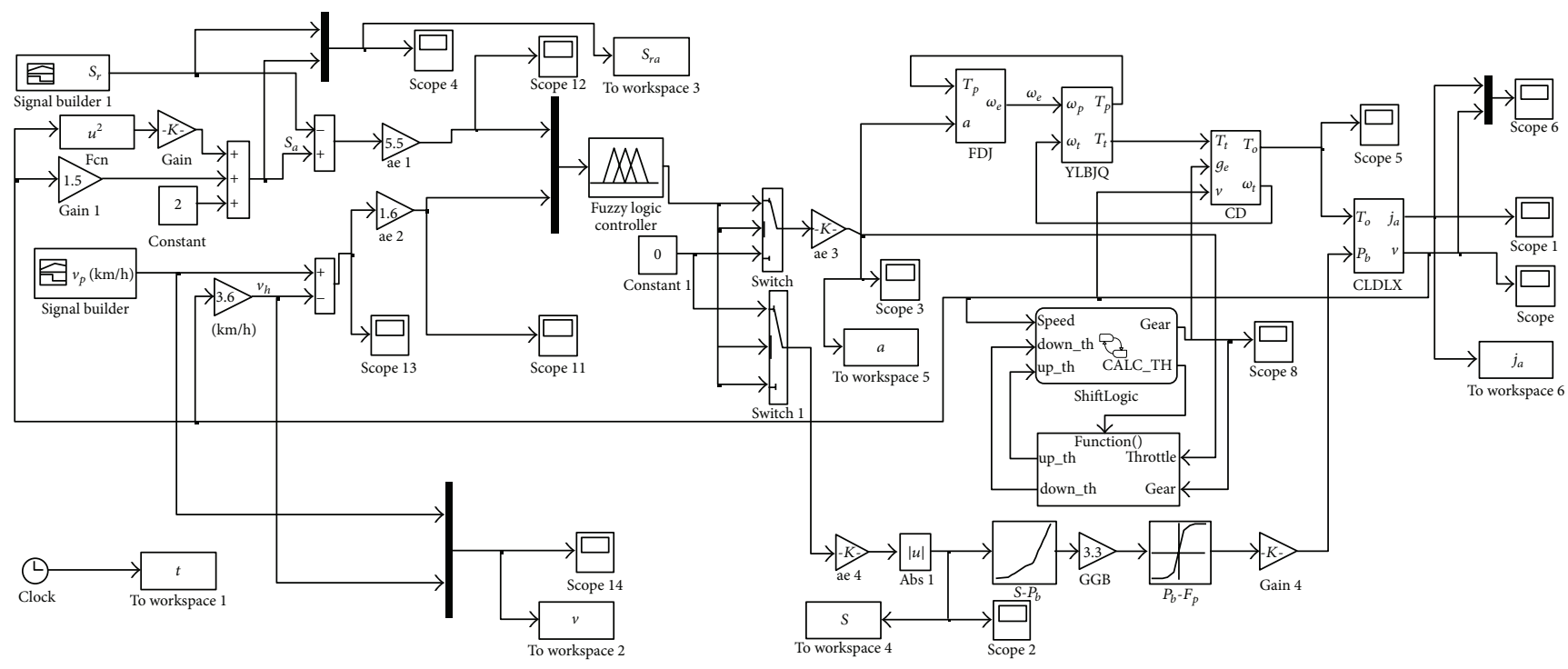

FIGURE 7: Simulation module of automobile intelligent cruise control based on MATLAB/Simulink. 
TABLE 2: Relationship of brake pedal travel $S$ and pedal force $P_{b}$.

\begin{tabular}{lcccccccc}
\hline Braking pedal force $P_{b} / \mathrm{N}$ & 20 & 40 & 60 & 80 & 100 & 120 & 140 & 160 \\
Braking pedal travel $S / \mathrm{mm}$ & 22.96 & 26.46 & 29.83 & 33.19 & 36.56 & 39.92 & 43.28 & 46.63 \\
Braking pedal force $P_{b} / \mathrm{N}$ & 180 & 200 & 250 & 300 & 350 & 400 & 450 & 500 \\
Braking pedal travel $S / \mathrm{mm}$ & 49.97 & 53.24 & 55.96 & 57.36 & 58.77 & 60.17 & 61.57 & 62.97 \\
\hline
\end{tabular}

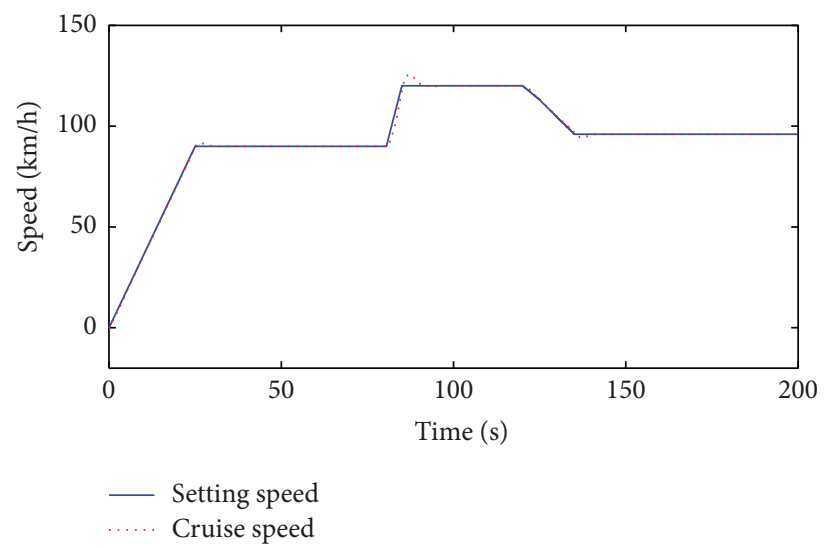

FIGURE 8: Simulation result of the high-speed condition.

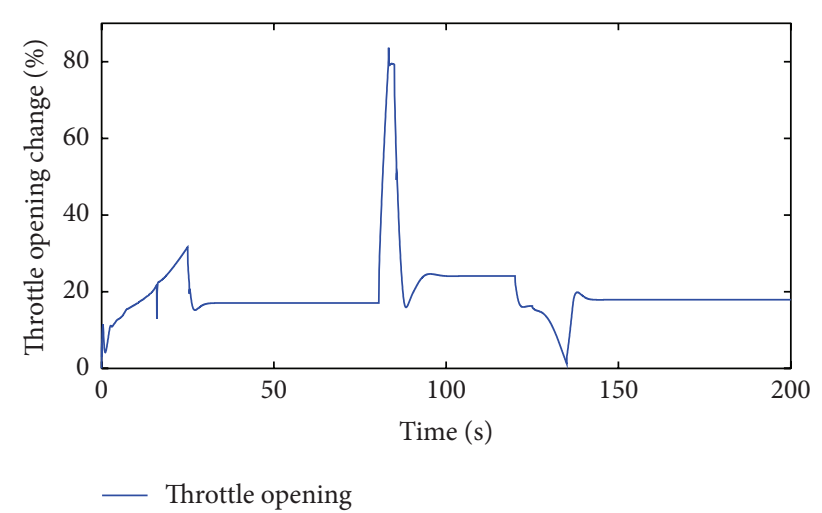

FIGURE 9: The throttle opening change of high-speed condition.

Figure $6(\mathrm{a}) . I_{e}$ denotes the moment of inertia on the engine flywheel and $\omega_{e}$ represents the engine's magnitude of angular velocity.

In (3), $T_{b f}$ and $T_{b r}$ represent the brake torque of the front and rear wheel, and it has been deduced by the following formula:

$$
\frac{T_{b f}+T_{b r}}{r}=K_{b} P_{b} .
$$

$K_{b}$ is the proportionality coefficient for brake system and $P_{b}$ denotes the pressure of brake master cylinder when brake pedal is pushed. In this paper, the braking pedal travel $S$ is one of the output variables of the longitudinal controller. So, it will need to convert the pedal force $P_{b}$ into pedal travel $S$.

Using MATLAB/Simulink, a relational expression is obtained by fitting test data on the brake pedal travel $S$ and

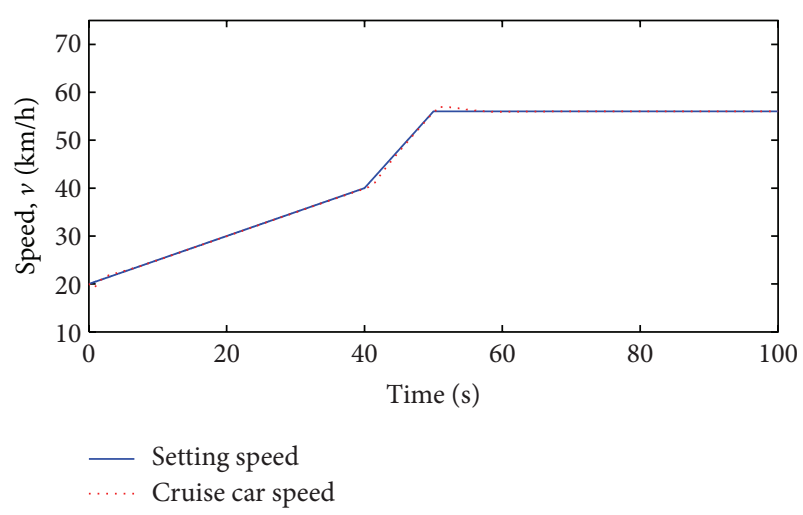

FIGURE 10: Simulation result of the low-speed condition.

pedal force $P_{b}$ (see Table 2) as follows: $a_{1}=0.0058, a_{2}=$ $-0.3668, a_{3}=7.6646, a_{4}=3.4565$. Consider

$$
P_{b}(S)=a_{1} S^{3}+a_{2} S^{2}+a_{3} S+a_{4} .
$$

Figure 6 depicts the engine torque characteristic map and the gear switch logic of automatic transmission used in the module of vehicle longitude dynamics system. Using look-up table and state flow in Simulink, the test data from the engine torque characteristic and the gear switch logic of automatic transmission in Figure 6 has been loaded to the simulation module (see Figure 7).

\section{Simulation Results}

In order to examine the feasibility and effectiveness of the proposed intelligent control strategy, the function on the 


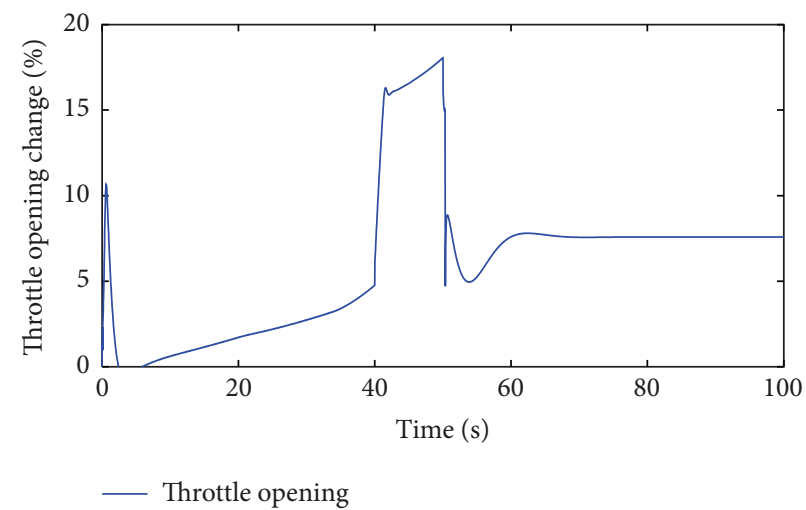

FIGURE 11: The throttle opening change of low-speed condition.

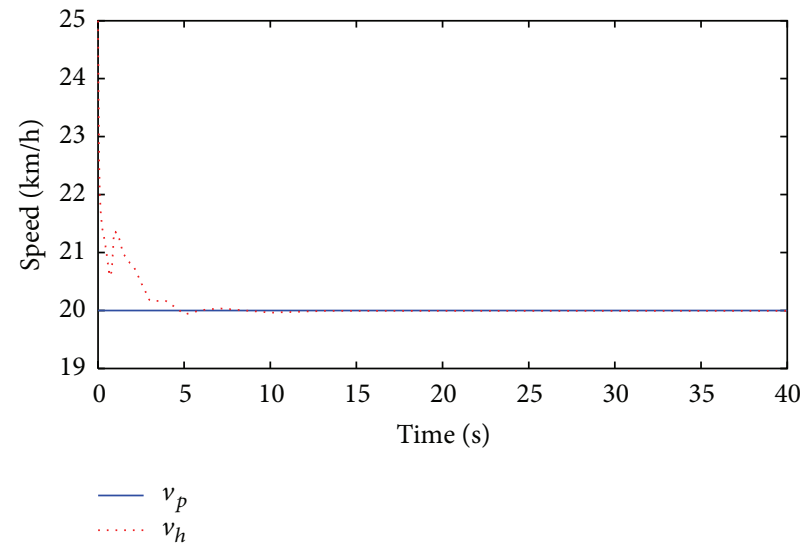

(a) Velocity compared result between the two vehicles

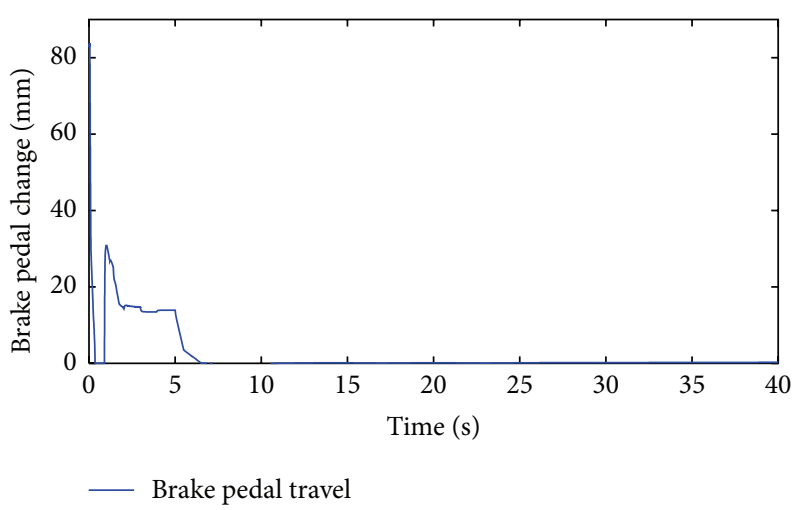

(c) Brake pedal change curve

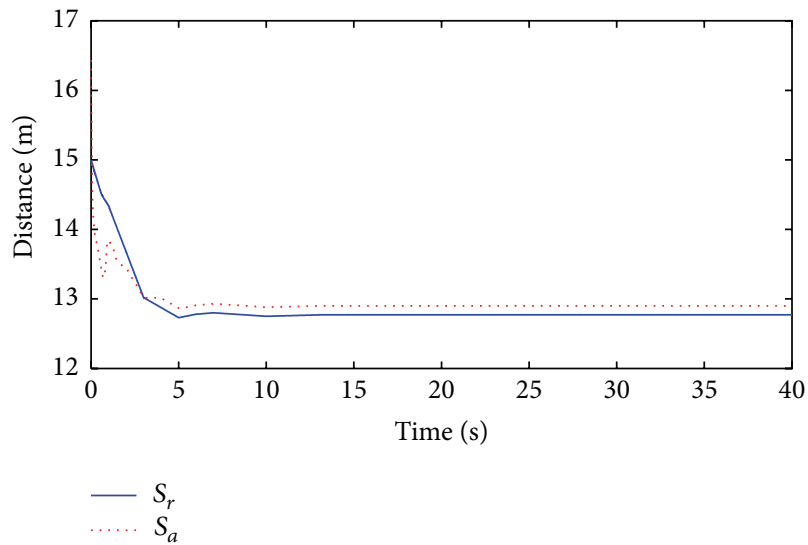

(b) Distance compared result between the two vehicles

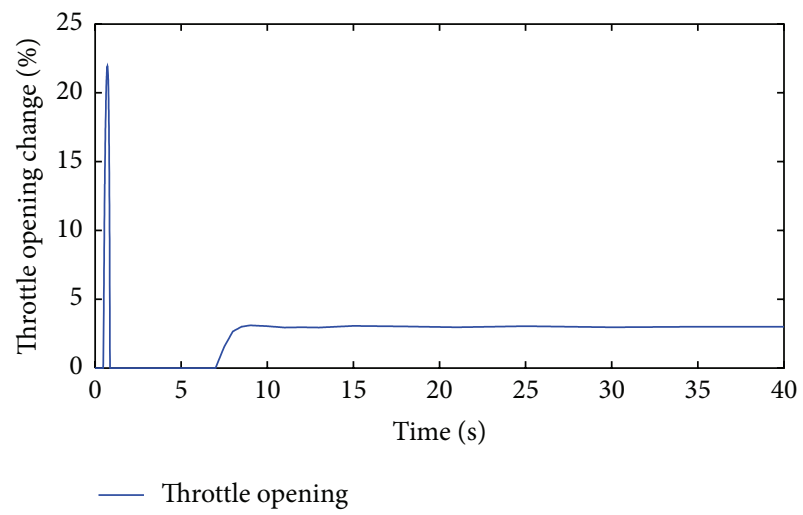

(d) Throttle opening change curve

FIGURE 12: Simulation result on the condition of $v_{h}>v_{P}$ and $S_{r}<S_{a}$ for Case 1.

intelligent cruise control system is simulated adopting Simulink aiming at different working conditions on the city road. First, it is necessary to validate the availability of the vehicle dynamics model established above on the intelligent cruise system. We can do that by testing the control effect on applying the above established model to CCS system to illustrate the rationality of the dynamics model.
Figures 8-11, respectively, show the comparison result of speed matching and the change of the throttle opening adopting the tested CCS system based on the dynamics model. You can see from Figures 8 and 11 that the speed of the cruise vehicle is perfect to adapt the presetting speed and that illustrates availability of the cruise system dynamics model established in this paper. 


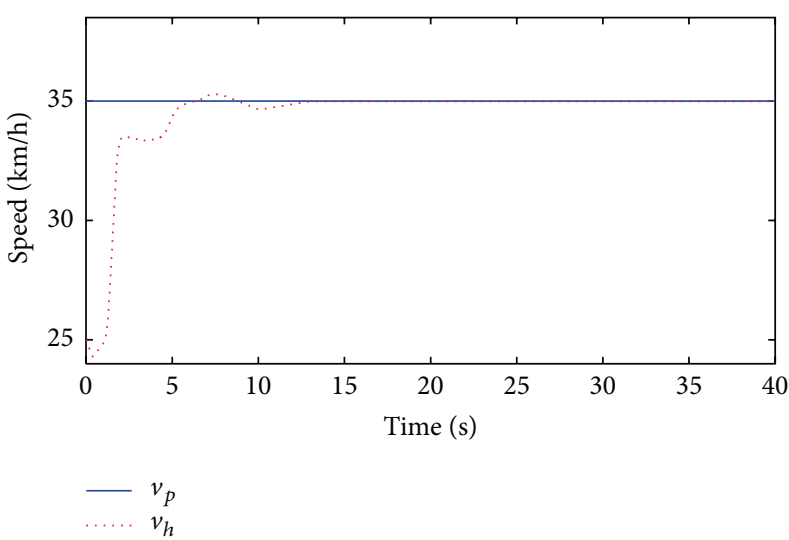

(a) Velocity compared result between the two vehicles

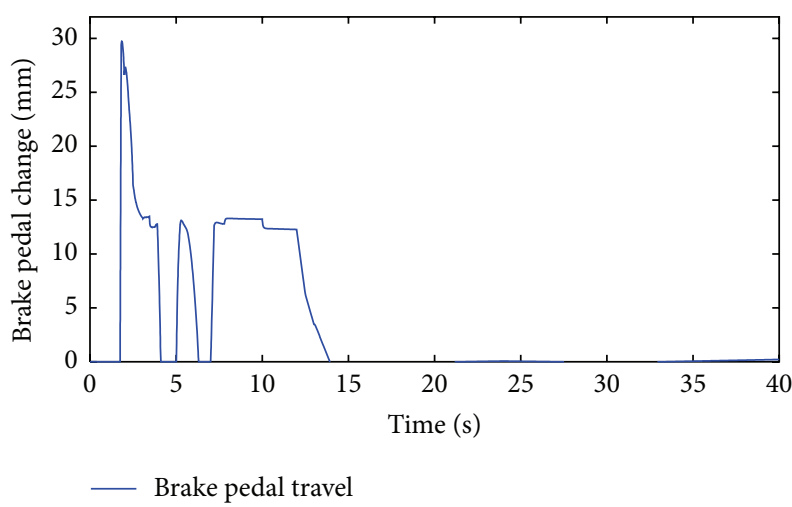

(c) Brake pedal change curve

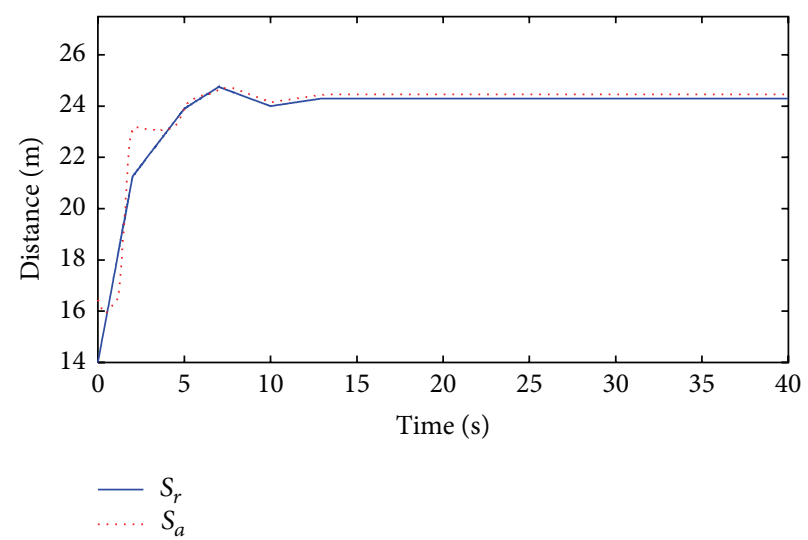

(b) Distance compared result between the two vehicles

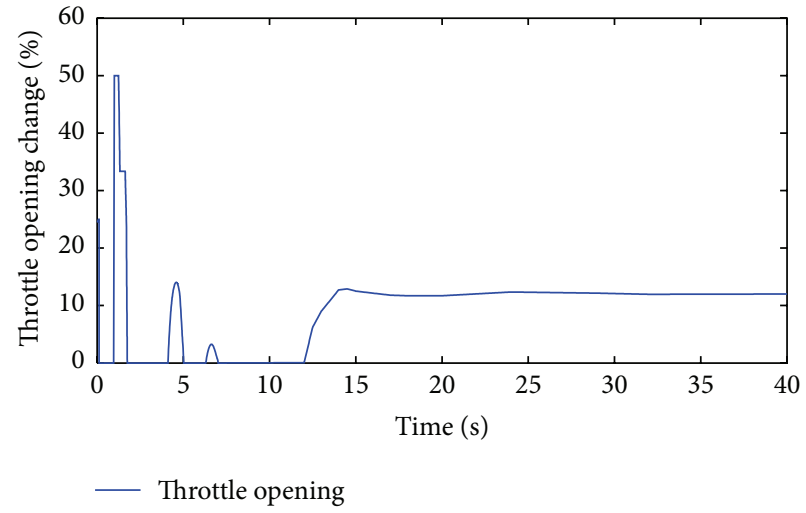

(d) Throttle opening change curve

Figure 13: Simulation result for Case 2.

On the basis of the feasible dynamics model, the control function on the intelligent cruise system is further tested under different working conditions on the city road taking the test data of $1.6 \mathrm{~L}$ vehicle with four speed auto-transmissions (the transmission ratios are $2.71,1.44,1$, and 0.74 separately) as an example. In case of intelligent following mode, some typical cases are listed as follows.

Case 1. The cruise vehicle followed the preceding low-speed target vehicle and the distance between the two vehicles is not secure enough. Taking this one step further, at the initial stage the cruise vehicle velocity $v_{h}$ is greater than the preceding vehicle velocity $v_{p}$, and the actual relative distance $S_{r}$ between the two vehicles is less than the theoretical safety distance $S_{a}$.

As seen from Figure 12 of the simulation result in Case 1 , the cruise vehicle is immediately slowed down owing to the existing security risk. However, it is worth mentioning that the result in Figure 12(c) denotes that an action regulated the braking pedal to be executed for reducing the cruise vehicle's velocity aiming at eliminated insecurity. Then, the cruise vehicle repeatedly adjusts the throttle to match the target vehicle's velocity for ensuring that the distance between two vehicles is safe.
Case 2. The cruise vehicle followed the preceding higherspeed vehicle or a vehicle with the higher-speed suddenly cuts into the front of the cruise vehicle. Taking this one step further, at the initial stage the velocity $v_{h}$ of the cruise vehicle is much less than the velocity $v_{p}$ of the preceding target vehicle, and the relative distance $S_{r}$ between the two vehicles is less than the theoretical safety distance $S_{a}$. So, there is a potential security liability between the two vehicles.

Figure 13 shows the simulation result of Case 2. As can be seen from Figure 13, the cruise vehicle theoretically should slow down because the relative distance $S_{r}$ between the two vehicles is less than the theoretical safety distance $S_{a}$, but the braking pedal was not activated at the initiative time. On the contrary, owing to the larger velocity difference between two vehicles the cruise vehicle's throttle was activated for rapidly approaching the velocity of the preceding target vehicle. Then, the cruise vehicle executes repeatedly the adjusted action from the throttle to braking pedal or otherwise and finally matches the velocity of the preceding vehicle.

Case 3. The cruise vehicle travels at 25 thousand miles an hour. A car in front of the cruise vehicle about 15 meters goes at 5 thousand miles an hour and stops after 5 seconds. 

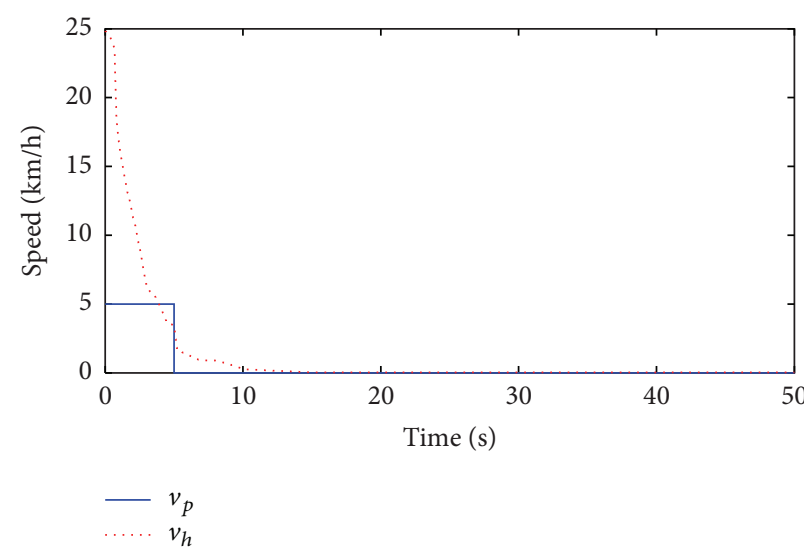

(a) Velocity compared result between the two vehicles

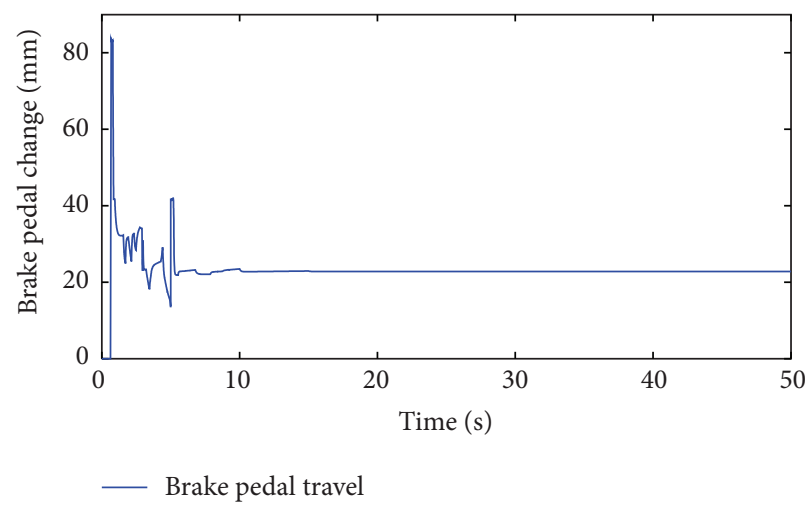

(c) Brake pedal change curve

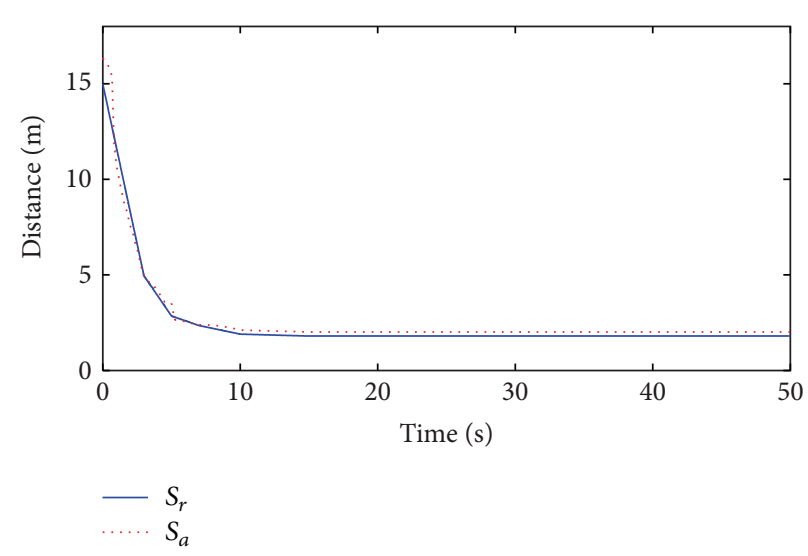

(b) Distance compared result between the two vehicles

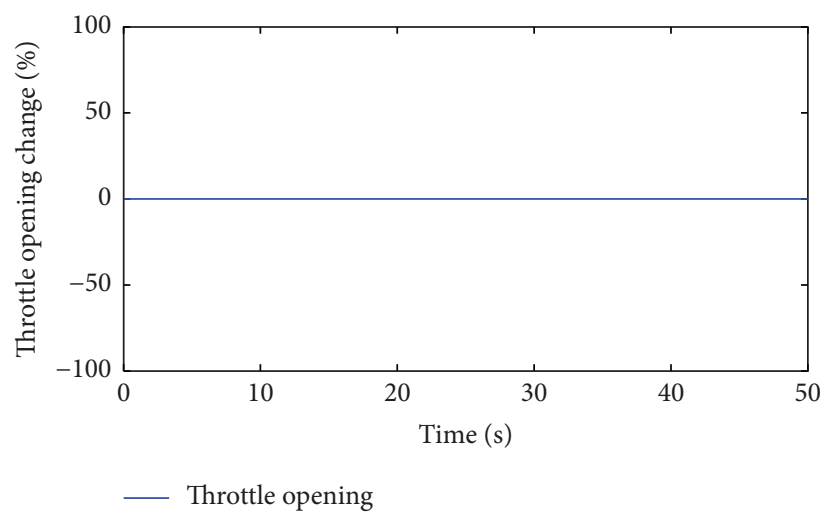

(d) Throttle opening change curve

FIGURE 14: Simulation result for Case 3.

The cruise vehicle follows the preceding vehicle at lowerspeed and stopped eventually.

You can see from Figure 14(b) that the relative distance $S_{r}$ between the two vehicles is less than the theoretical safety distance $S_{a}$. But the cruise vehicle velocity $v_{h}$ is greater than the preceding vehicle velocity $v_{p}$ (see Figure $14(\mathrm{a})$ ), so the braking pedal is to be executed for reducing the cruise vehicle's velocity aiming at eliminated insecurity. Then, the cruise vehicle repeatedly adjusts the braking pedal to stabilize for reducing oneself velocity until it stops in the range of stopping distance 2 meters (see Figures 14(b) and 14(c)). During the whole process, the cruise vehicle's throttle opening is always zero because of the braking pedal to be activated. The simulation results show that the control strategy possesses the automated Stop \& Go function.

Case 4. The cruise vehicle followed the preceding high-speed target vehicle and the distance between the two vehicles is secure enough. The preceding target vehicle increases its own speed from 80 to 100 kilometers per hour after $40 \mathrm{~s}$. The cruise vehicle accelerates from static condition to 80 kilometers per hour, following the preceding vehicle under the condition of ensuring the safe distance.
Figure 15 depicts the simulation result of Case 4 . It is clearly observed that the cruise vehicle quickly increases velocity up to 80 kilometers per hour by increasing the throttle opening at first and keeps the unchanged throttle opening $40 \mathrm{~s}$ ago. Then, the cruise vehicle continues to increase the throttle opening for following the preceding target vehicle's velocity. When the velocity of the cruise vehicle matches the velocity of the preceding vehicle, the throttle opening will basically remain unchanged while ensuring that the relative distance between the two vehicles is in the range of safe distance. It is worth mentioning that the result in Figure 15(c) denotes that the braking pedal travel remains in motionless state during the whole control process that is closer to the actual.

Case 5. A comprehensive status is proposed for simulating the cruise vehicle which actively follows the preceding vehicle to accelerate, slow down to stop, and restart up to a preset velocity. At the initial stage the velocity $v_{h}$ of cruise vehicle is greater than the velocity $v_{p}$ of preceding vehicle and the relative distance $S_{r}$ between the two vehicles approaches the theoretical safety distance $S_{a}$.

As seen from Figures 16(c) and 16(d) of the simulation result in Case 5, within two seconds of the initial stage the 


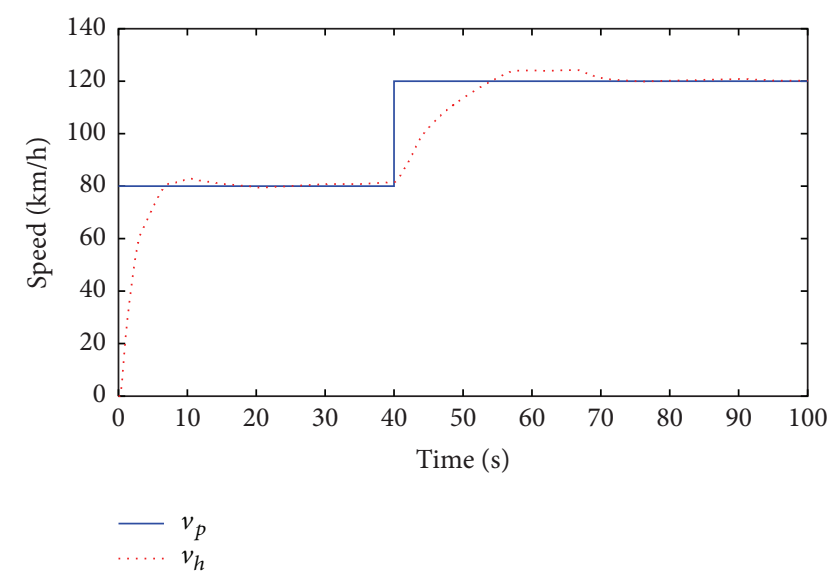

(a) Velocity compared result between the two vehicles

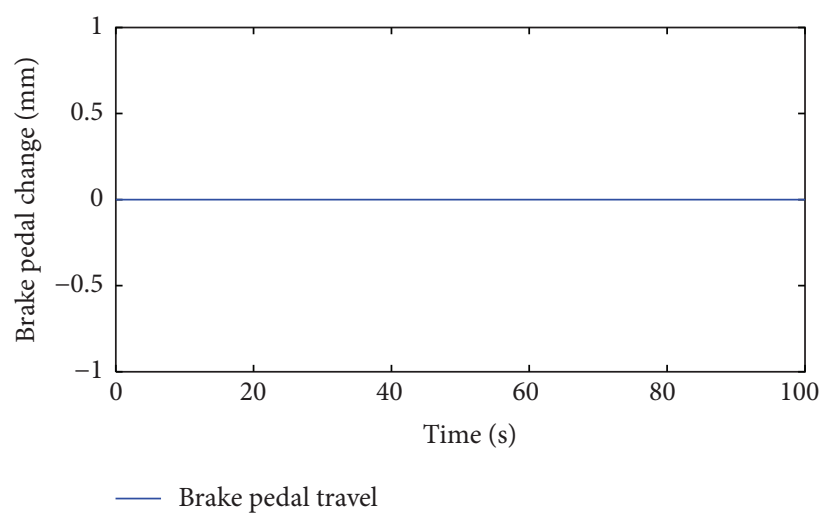

(c) Brake pedal change curve

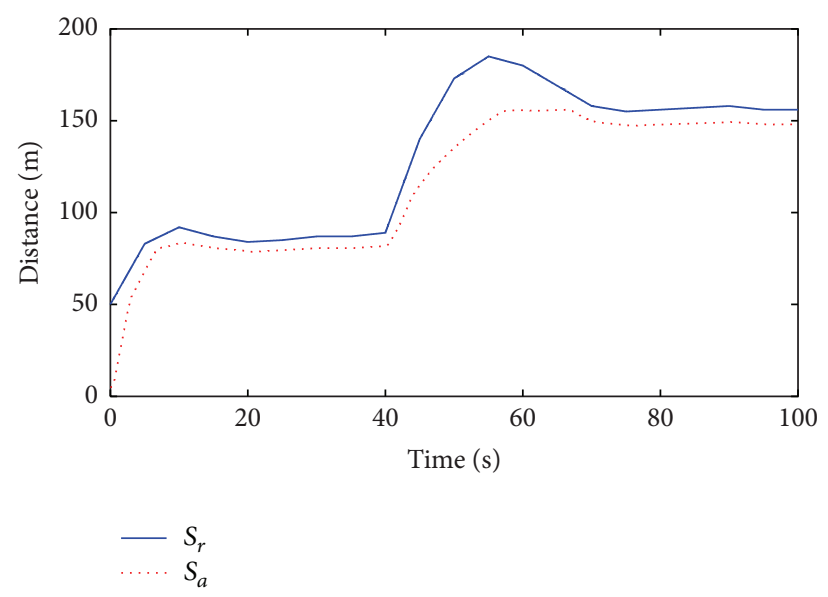

(b) Distance compared result between the two vehicles

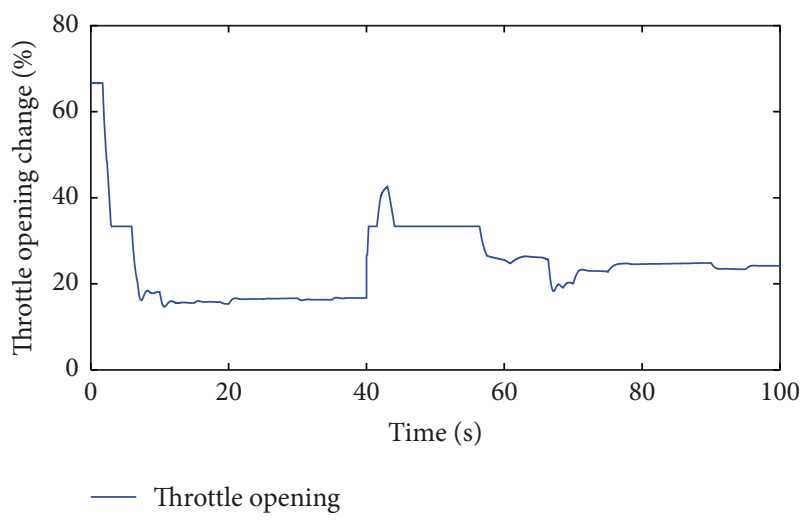

(d) Throttle opening change curve

FIGURE 15: Simulation result for Case 4.

braking pedal of the cruise vehicle was activated to reduce oneself velocity $v_{h}$, but then the throttle of the cruise vehicle was activated because the relative distance $S_{r}$ between the two vehicles is slightly larger than the theoretical safety distance $S_{a}$. At this time of $30 \mathrm{~s}$, the cruise vehicle changes the braking pedal and the throttle in the turn to adapt the wave process owing to the change of the distance and velocity between the two vehicles. At this time of $60 \mathrm{~s}$, the cruise vehicle follows actively the preceding vehicle to slow down until stopping by activated the braking pedal. Worthy of mention is the fact that the safe stopping distance between the two vehicles is set to 2 meters. At this time of $95 \mathrm{~s}$, the cruise vehicle actively adjusts the throttle to follow the change of the preceding vehicle from the idle state to speed up again. In a word, the cruise vehicle changes the braking pedal and the throttle in the turn to adapt the wave process if the change of the distance or velocity between the two vehicles occurs.

\section{Conclusions}

This paper has proposed an intelligent fuzzy control strategy for combining the throttle and braking control to realize ACC and Stop \& Go control function in a unified control framework. Adopting MATLAB/Simulink, a simulation module of automobile intelligent cruise control is created based on the vehicle dynamics modeling taking the test data of $1.6 \mathrm{~L}$ vehicle with four speed auto-transmissions as an example. The results of the experiment cases show that the presented fuzzy control strategy is effective and feasible and it is not only achieving high-velocity ACC and low-velocity Stop \& Go control function but also fulfilling conventional cruise control function. As future work, we intend to build the intelligent cruise system's prototypes through the built simulation module and develop products by single-chip technology.

\section{Competing Interests}

The authors declare that they have no competing interests.

\section{Acknowledgments}

This work was supported in part by the Natural Science Foundation of China under Grant 61473139 and the joint fund of the Natural Science Foundation of Liaoning Province of 

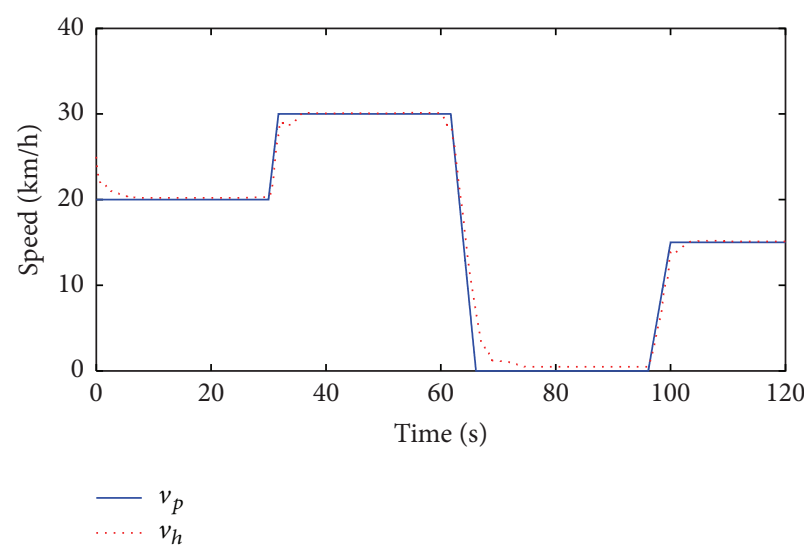

(a) Velocity compared result between the two vehicles

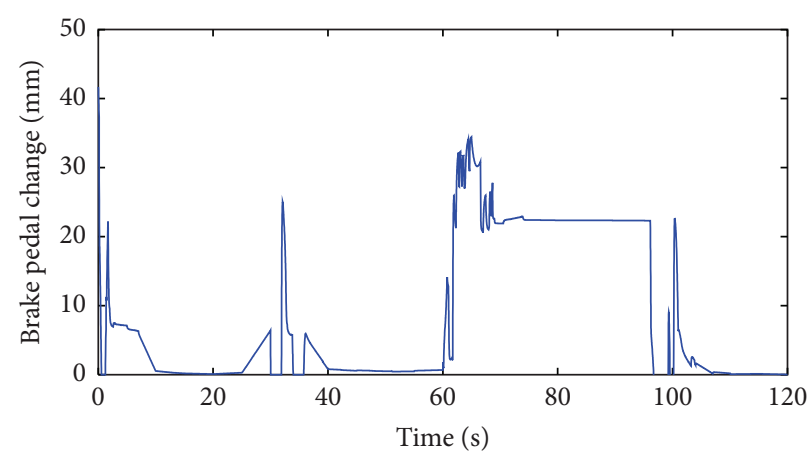

- Brake pedal travel

(c) Brake pedal change curve

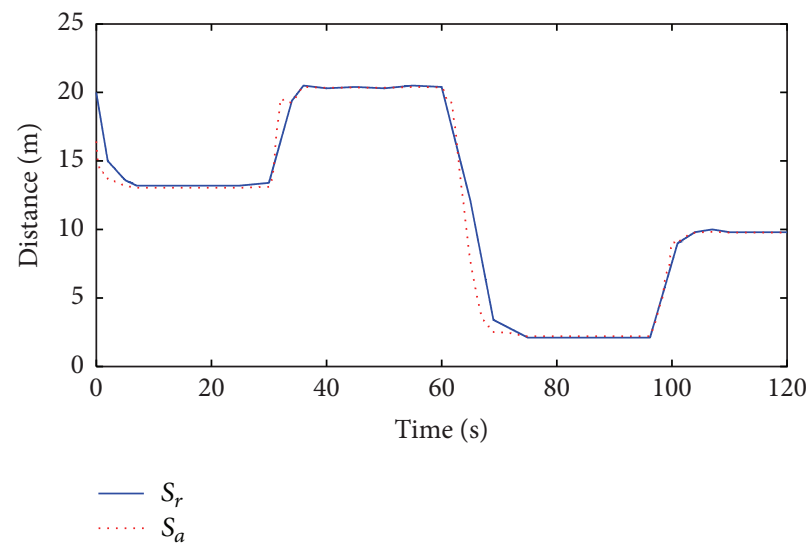

(b) Distance compared result between the two vehicles

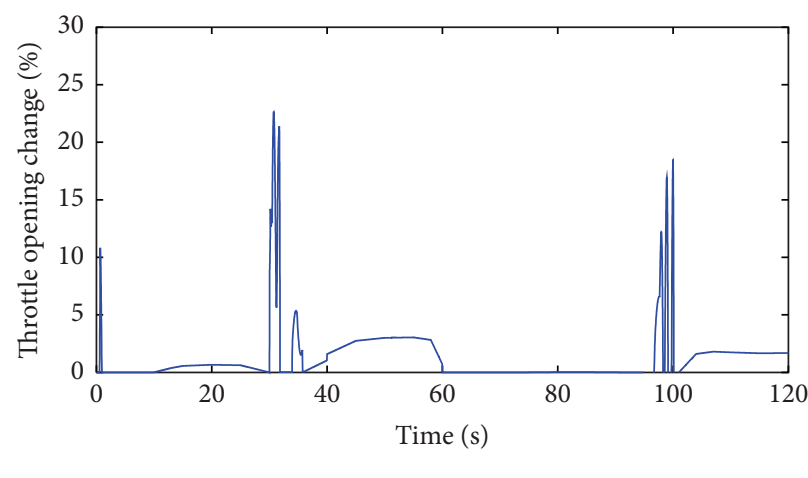

- Throttle opening

(d) Throttle opening change curve

FIGURE 16: Simulation result for Case 5.

China, and the general project for the Education Department of Liaoning Province of China under Grant L2014240.

\section{References}

[1] D. Corona and B. De Schutter, "Adaptive cruise control for a SMART car: a comparison benchmark for MPC-PWA control methods," IEEE Transactions on Control Systems Technology, vol. 16, no. 2, pp. 365-372, 2008.

[2] Y. Yamamura, Y. Seto, H. Nishira, and T. Kawabe, "An ACC design method for achieving both string stability and ride comfort," Journal of System Design and Dynamics, vol. 2, no. 4, pp. 979-990, 2008.

[3] N. Benalie, W. Pananurak, S. Thanok, and M. Parnichkun, "Improvement of adaptive cruise control system based on speed characteristics and time headway," in Proceedings of the IEEE/ RSJ International Conference on Intelligent Robots and Systems (IROS '09), pp. 2403-2408, St. Louis, Miss, USA, October 2009.

[4] S. H. Jeong, J. E. Lee, S. U. Choi, J. N. Oh, and K. H. Lee, “Technology analysis and low-cost design of automotive radar for adaptive cruise control system," International Journal of Automotive Technology, vol. 13, no. 7, pp. 1133-1140, 2012.

[5] M. H. Lee, H. G. Park, S. H. Lee, K. S. Yoon, and K. S. Lee, "An adaptive cruise control system for autonomous vehicles," International Journal of Precision Engineering and Manufacturing, vol. 14, no. 3, pp. 373-380, 2013.
[6] J.-J. Martinez and C. Canudas-de-Wit, "A safe longitudinal control for adaptive cruise control and stop-and-go scenarios," IEEE Transactions on Control Systems Technology, vol. 15, no. 2, pp. 246-258, 2007.

[7] C.-C. Tsai, S.-M. Hsieh, and C.-T. Chen, "Fuzzy longitudinal controller design and experimentation for adaptive cruise control and stop\&Go," Journal of Intelligent and Robotic Systems: Theory and Applications, vol. 59, no. 2, pp. 167-189, 2010.

[8] P. Shakouri, A. Ordys, and M. R. Askari, "Adaptive cruise control with stop \& go function using the state-dependent nonlinear model predictive control approach," ISA Transaction, vol. 51, no. 5, pp. 622-631, 2012.

[9] K. Cho, S. B. Choi, S. Choi, and M. Son, "Adaptive neural network based fuzzy control for a smart idle stop and go vehicle control system," International Journal of Automotive Technology, vol. 13, no. 5, pp. 791-799, 2012.

[10] P. Shakouri and A. Ordys, "Nonlinear model predictive control approach in design of adaptive cruise control with automated switching to cruise control," Control Engineering Practice, vol. 26, no. 1, pp. 160-177, 2014.

[11] Y.-J. Liu and S. Tong, "Adaptive fuzzy control for a class of unknown nonlinear dynamical systems," Fuzzy Sets and Systems, vol. 263, pp. 49-70, 2015.

[12] G. Lai, Z. Liu, Y. Zhang, C. L. P. Chen, S. Xie, and Y.-J. Liu, "Fuzzy adaptive inverse compensation method to tracking control of uncertain nonlinear systems with generalized actuator dead zone," IEEE Transactions on Fuzzy Systems, 2016. 
[13] Y. J. Liu, Y. Gao, S. S. Tong, and Y. M. Li, "Fuzzy approximationbased adaptive backstepping optimal control for a class of nonlinear discrete-time systems with dead-zone," IEEE Transactions on Fuzzy Systems, vol. 24, no. 1, pp. 16-28, 2016.

[14] G.-X. Wen, C. L. P. Chen, Y.-J. Liu, and Z. Liu, "Neural-networkbased adaptive leader-following consensus control for secondorder non-linear multi-agent systems," IET Control Theory \& Applications, vol. 9, no. 13, pp. 1927-1934, 2015.

[15] S. C. Tong, L. L. Zhang, and Y. M. Li, “Observed-based adaptive fuzzy decentralized tracking control for switched uncertain nonlinear large-scale systems with dead zones," IEEE Transactions on Systems, Man, and Cybernetics: Systems, vol. 46, no. 1, pp. 37-47, 2016.

[16] C. L. P. Chen, Y.-J. Liu, and G.-X. Wen, "Fuzzy neural networkbased adaptive control for a class of uncertain nonlinear stochastic systems," IEEE Transactions on Cybernetics, vol. 44, no. 5, pp. 583-593, 2014.

[17] Y.-J. Liu and S. C. Tong, "Barrier Lyapunov functions-based adaptive control for a class of nonlinear pure-feedback systems with full state constraints," Automatica, vol. 64, pp. 70-75, 2016.

[18] W. He, S. Nie, T. Meng, and Y.-J. Liu, "Modeling and vibration control for a moving beam with application in a drilling riser," IEEE Transactions on Control Systems Technology, In press.

[19] J. E. Naranjo, C. Gonzàlez, R. G. García, and T. D. Pedro, "ACC+Stop\&go maneuvers with throttle and brake fuzzy control," IEEE Transactions on Intelligent Transportation Systems, vol. 7, no. 2, pp. 213-224, 2006.

[20] X. F. Pei, Z. D. Liu, G. C. Ma, and Z. Q. Qi, "An adaptive cruise control system based on throttle/brakes combined control," Automotive Engineering, vol. 35, no. 4, pp. 375-380, 2013.

[21] V. Milanés, J. Villagrá, J. Godoy, and C. González, “Comparing fuzzy and intelligent PI controllers in stop-and-go manoeuvres," IEEE Transactions on Control Systems Technology, vol. 20, no. 3, pp. 770-778, 2012.

[22] P. Shakouri, J. Czeczot, and A. Ordys, "Simulation validation of three nonlinear model-based controllers in the adaptive cruise control system," Journal of Intelligent and Robotic Systems: Theory and Applications, vol. 80, no. 2, pp. 207-229, 2015.

[23] Y.-J. Liu, S. C. Tong, D.-J. Li, and Y. Gao, "Fuzzy adaptive control with state observer for a class of nonlinear discrete-time systems with input constraint," IEEE Transactions on Fuzzy Systems, 2015.

[24] W. He, W. Ge, Y. Li, Y.-J. Liu, C. Yang, and C. Sun, "Model identification and control design for a humanoid robot," IEEE Transactions on Systems, Man, and Cybernetics: Systems, 2016.

[25] Y. Gao and Y.-J. Liu, "Adaptive fuzzy optimal control using direct heuristic dynamic programming for chaotic discretetime system," Journal of Vibration and Control, vol. 22, no. 2, pp. 595-603, 2016. 


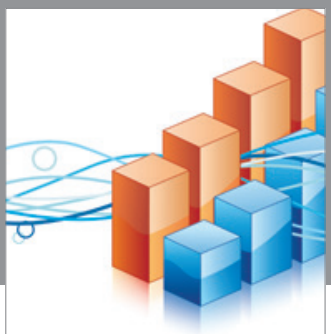

Advances in

Operations Research

vatem alat4

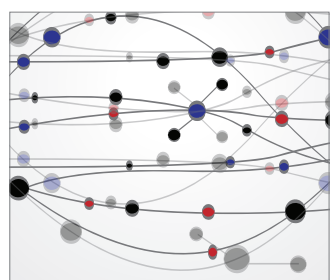

\section{The Scientific} World Journal
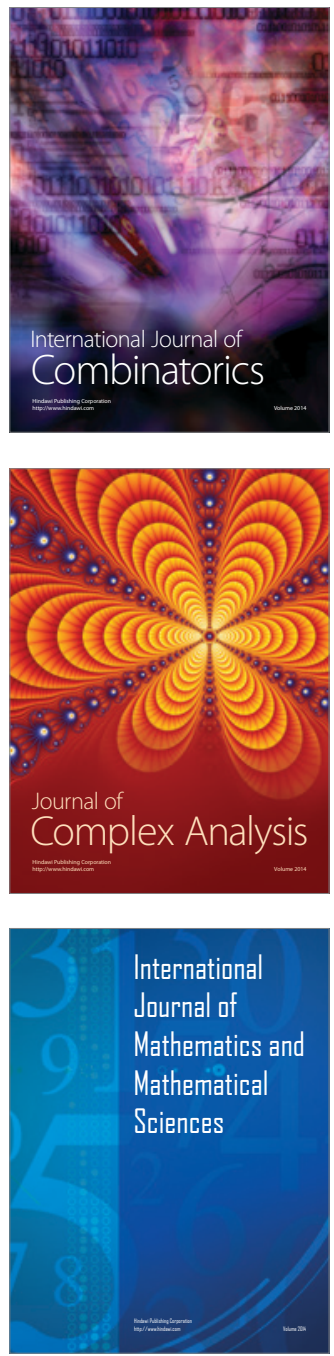
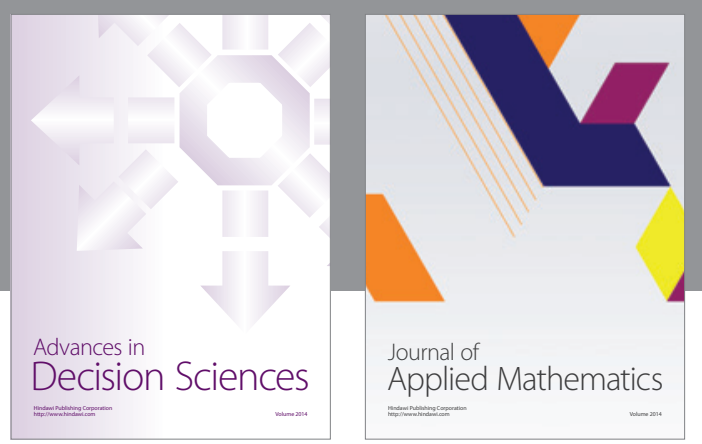

Algebra

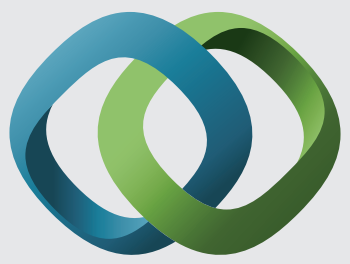

\section{Hindawi}

Submit your manuscripts at

http://www.hindawi.com
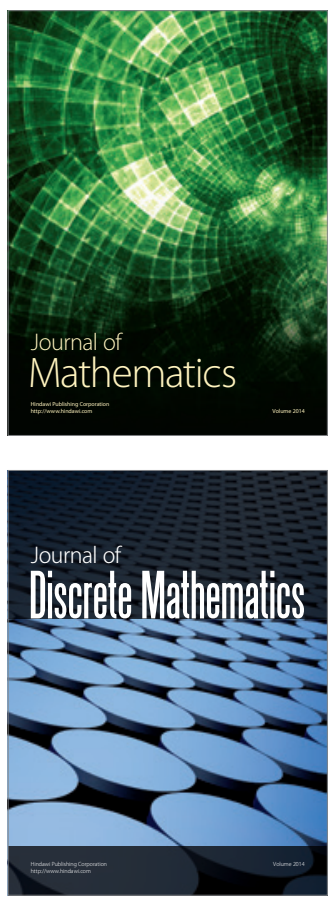

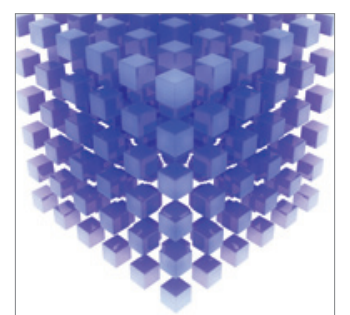

Mathematical Problems in Engineering
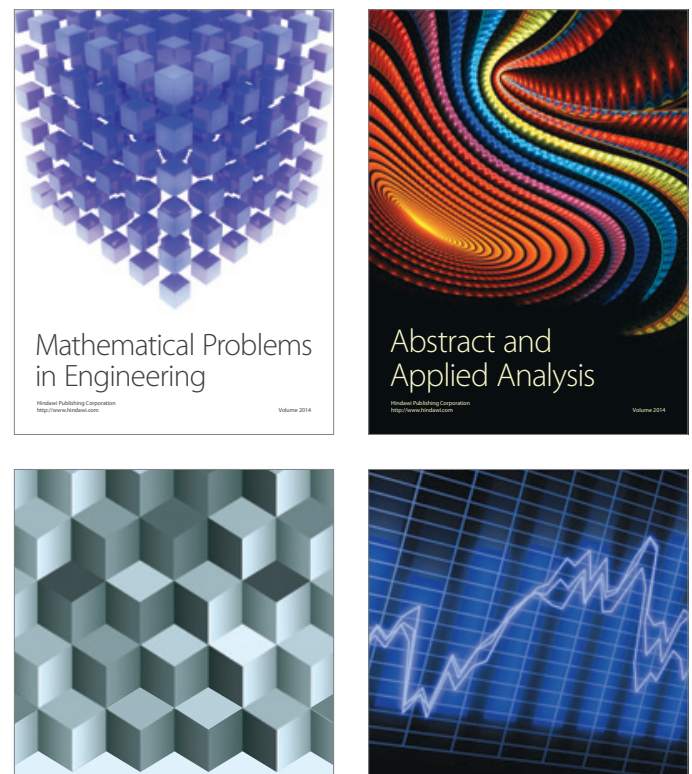

Journal of

Function Spaces

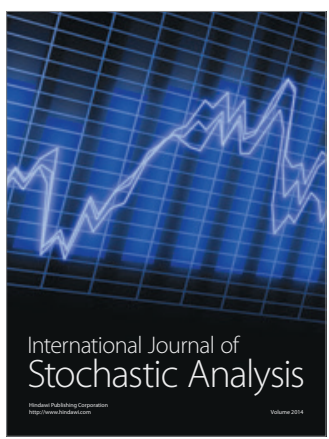

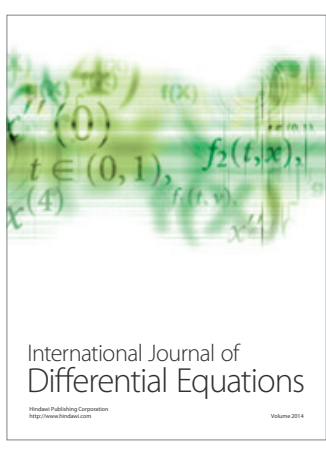
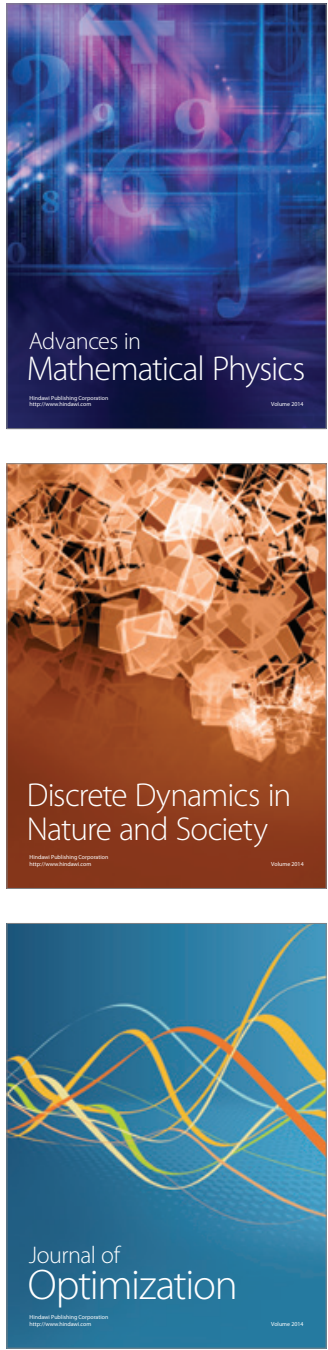